\title{
"En el panteón". Poema del escritor y diplomático mexicano Joaquín Gómez Vergara traducido y musicalizado al catalán
}

\section{"En el panteón". Poem by Mexican Writer and Diplomat Joaquín Gómez Vergara Translated and Musicalized into Catalan}

\author{
Lilia Vieyra Sánchez \\ Universidad Nacional Autónoma de México \\ Instituto de Investigaciones Bibliográficas \\ vieyra69@yahoo.com.mx
}

\section{RESUMEN}

Indagar sobre el desempeño de Joaquín Gómez Vergara como oficial de la Legación de México en España a las órdenes del general Ramón Corona permitió rescatar su poema "En el panteón", que se identificó en una partitura para voz y piano traducida por el compositor catalán Climent Cuspinera Oller y musicalizada por su compatriota José Ribera Miró. El artículo difunde la manera en la que se ubicó este hallazgo literario y destaca el proceso de investigación para determinar cómo conocieron esos melómanos españoles la poesía de Gómez Vergara; asimismo, se establece que su fuente de transmisión fue Enrique de Olavarría y Ferrari, quien lo incluyó en su libro Poesías líricas, publicado en Madrid en 1878. Trece años más tarde, en Barcelona, un equipo conformado por Cuspinera y Ribera, al que se sumaron los editores Juan Bautista Pujol Riu y Felipe Pedrell, consideró de gran calidad el poema, por lo que decidieron publicarlo en la revista Ilustración Musical. Hispano-Americana, con el propósito de promover la unidad entre España y México a través de las letras y la música, aspecto poco abordado en la historiografía.

\section{Palabras Clave}

Joaquín Gómez Vergara, José Ribera Miró, Enrique de Olavarría, Climent Cuspinera Oller, Juan Bautista Pujol Riu, Felipe Pedrell, Ilustración Musical. Hispano-Americana.

\section{AbStract}

Research life and work of Joaquín Gómez Vergara, as an officer of the Legation of Mexico in Spain under General Ramón Corona, allowed to rescue his poem 
"En el panteón" that was identified in a score for voice and piano that the Catalan composer Climent Cuspinera Oller translated and his compatriot José Ribera Miró musicalized. The article disseminates the way in which this literary discovery was located and highlights the research process to establish how those Spanish music lovers met with the poetry of Gómez Vergara. Establishes that its origin is due to Enrique de Olavarría and Ferrari included in his book Poesías líricas published in Madrid in 1878. Thirteen years later, in Barcelona a team consisting of Cuspinera and Ribera, which editors joined Juan Bautista Pujol Riu and Felipe Pedrell, considered the quality of the poem so they decided to publish it in the magazine Ilustración Musical. Hispano-Americana, with the purpose of promoting the unity of Spain and Mexico through letters and music, an aspect that has not been addressed in historiography.

\section{KEYWORDS}

Joaquín Gómez Vergara, José Ribera Miró, Enrique de Olavarría, Climent Cuspinera Oller, Juan Bautista Pujol Riu, Felipe Pedrell, Ilustración Musical. HispanoAmericana.

RECEPCIÓN: 15/10/2018

ACEPTACIÓN: 29/01/2019

\section{Introducción}

En el año 2016, publiqué un acercamiento a la vida y obra del escritor jalisciense Joaquín Gómez Vergara (1840-1894), quien colaboró con el general Ramón Corona (1837-1889), enviado extraordinario y ministro plenipotenciario de México en España, durante el trienio de 1874 a 1877. Desde aquella fecha, consideré fundamental difundir la labor literaria de este diplomático mexicano, poco conocido en la historiografía, que divulgó su experiencia en el servicio exterior a través de una serie de epístolas publicadas en El Porvenir, periódico editado en la Ciudad de México, cuya lectura permite saber más sobre el ambiente cultural, político y social de Madrid (véase Vieyra, 2016: 127-250).

Durante estos años, he reunido y analizado dicha correspondencia, constituida por crónicas, cuadros de costumbres e informes diplomáticos. En el 2018, expuse los resultados de esa investigación en el $4^{\circ}$ Coloquio Prensa y Literatura y en el I Congreso Internacional de Literatura Mexicana. Siglos XIX y Xx. ${ }^{1}$ La indagación sobre

\footnotetext{
${ }^{1}$ El 2 de marzo de 2018 leí la ponencia "Joaquín Gómez Vergara en El Porvenir, entre el informe diplomático y la crónica (1874-1875)" en el $4^{\circ}$ Coloquio Prensa y Literatura, celebrado en El Colegio de San Luis. El 19 de junio de 2018 presenté "Los 'Cuadros madrileños'
} 


\section{“En el panteón”. Poema de Joaquín Gómez Vergara}

la presencia de Gómez Vergara en España me ha llevado a consultar libros, revistas y periódicos que pueden ofrecer información relacionada tanto a la estancia de este diplomático en Madrid como a la publicación de sus trabajos en Europa, pues, luego de servir a México en España, marchó a Italia y a Alemania para continuar con esa encomienda. La consulta del catálogo de la Biblioteca Nacional de España hizo posible encontrar, en su Biblioteca Digital Hispánica, la romanza "En el panteón”, poema de Joaquín Gómez Vergara que llamó la atención de músicos y editores en Barcelona, quienes decidieron traducirlo, musicalizarlo y difundirlo a través de la revista Ilustración Musical. Hispano-Americana en 1891.

El hallazgo del presente material generó diversas interrogantes en torno al motivo de su circulación en dicha revista: ¿cómo conocieron el poema esos catalanes?, ¿acaso Gómez Vergara tuvo contacto directo con los editores o les envió su composición para que la incluyeran como parte de un proyecto editorial que abarcara a México y España? A continuación, refiero algunas posibles respuestas a estos cuestionamientos.

En Madrid, Joaquín Gómez Vergara tuvo cercanía con Enrique de Olavarría y Ferrari (1844-1918), peninsular que residió en nuestro país por algún tiempo y que regresó a su patria en 1874, el mismo año en el que Gómez Vergara abandonó la suya para servir a ésta en el exterior. Olavarría destacó la calidad de la literatura mexicana en el ensayo "El arte literario en México. Apuntes para una historia de las letras españolas en América", publicado por entregas en la Revista de Andalucía (25 de enero-25 de septiembre de 1878) y, meses después, reunido en el libro El arte literario en México. Noticia biográfica y crítica de sus más notables escritores. ${ }^{2}$ Olavarría mencionó en esa obra algunos datos sobre el autor jalisciense y su trayectoria narrativa realizada en México, donde sacó a la luz: Quien mal anda mal acaba (1870), Fotografias a la sombra (1871) y Las cruces del santuario (1873). También, señaló que Gómez Vergara merecía reconocimiento como poeta lírico, cuyos romances vestía con "el severo y majestuoso ropaje de la fabla española del siglo xIII, manejada con recomendable acierto” (1878a: 208).

Además de difundir el panorama literario, Olavarría tenía el propósito de divulgar la poesía mexicana en España, motivo por el cual editó Poesías líricas en 1878. El madrileño solicitó a Joaquín Gómez Vergara un par de poemas que éste escribió especialmente para dicho libro. En 1872, Juan E. Barbero ya había publicado Lira de la juventud. Poesías mexicanas, en el que se agruparon poetas activos por aquellos años, pero no se incluyó a Gómez Vergara. Cabe decir que, en esa etapa, nuestro autor era poco conocido en el ambiente literario, pues, procedente de Jalisco, fijó su residencia en la

de Joaquín Gómez Vergara (1875)" en el I Congreso Internacional de Literatura Mexicana. Siglos XIX y Xx. Rescate y edición, Prensa y literatura, Géneros literarios, Historias.

${ }^{2}$ Este tema lo abordé con más detalle en la ponencia titulada "Las ediciones de El arte literario en México de Enrique de Olavarría y Ferrari”, dictada el 8 de abril de 2015 en el Auditorio José María Vigil del Instituto de Investigaciones Bibliográficas. 
Ciudad de México apenas en 1872; aunque ya contaba con los libros mencionados -impresos por Ignacio Cumplido-, su nombre estaba más ligado al periodismo y a la narrativa, con incipientes dotes poéticas, ante todo jocoserios y de corte político, sus textos aparecieron en las páginas de Zuan Panadero, El Siglo Diez y Nueve, Fuan Diego, El Espanto, El Domingo, La Edad Feliz, El Federalista y El Eco de Ambos Mundos.

La nostalgia que Gómez Vergara sentía en España por su terruño le llevó a escribir "Mis montañas", en el que, con pesadumbre, expresó:

Pero estoy lejos, muy lejos, de aquella tierra bendita donde las flores no mueren ni el helado cierzo silba; do el árbol no se despoja, y entre sus frondas abriga enjambres de colibríes que al volar rápidos brillan cual primorosa cascada de luciente pedrería. Allá es más azul el cielo, allá más hermoso brilla la luna, y el sol ardiente benigno calor envía; allá el cansado viajero frescura y descanso brindan el platanar rumoroso y las fuentes cristalinas; allí se meció mi cuna, allí mi madre querida me alimentaba a su seno y en sus brazos me adormía; allí pasé de mi infancia aquellas horas benditas en que el alma no conoce los pesares de la vida; y allí de mis tiernos padres las veneradas cenizas duermen, bajo los rosales que sus rosas no marchitan. ¡Oasis del Nuevo Mundo! ¡Adorada patria mía!

Quiera Dios que vuelva a verte, y que al acabar mi vida, exhale mi último aliento entre tus fragantes brisas, 


\title{
“En el panteón”. Poema de Joaquín Gómez Vergara
}

\author{
bajo tu estrellado cielo, \\ y escuchando la armonía \\ de tus pájaros cantores \\ que en tus arboledas trinan. \\ ¡Montañas americanas!... \\ ¡Hermosas montañas mías!... (Gómez: 109-110).
}

Un año después, el escritor Juan de Dios Peza, secretario de la Legación de México en España, publicó en Madrid La lira mexicana, y es probable que haya consultado la obra de Olavarría, pues ahí incluyó el poema "Mis montañas", tal vez interesado en el carácter nacionalista de los versos de Joaquín Gómez Vergara (véase Peza: 197-200). ${ }^{3}$

La década de 1870 es fecunda en cuanto a la presencia de peninsulares que emigraron a México y que, al regresar a su país natal, se interesaron en reivindicar la calidad cultural de la nación adoptiva. Entre los españoles que publicaron libros y artículos en revistas para hablar de las letras mexicanas, se encuentra el cartagenero Adolfo Llanos y Alcaraz (1841-19??), quien, un lustro después de la edición de la obra poética de Olavarría, escribió "Estado actual de la cultura literaria en Méjico" para la Revista de España, en su número correspondiente a enero-febrero de 1883; ahí mencionó a Gómez Vergara y reprodujo “En el panteón”. Es probable que Adolfo Llanos basara esta selección en las Poesías líricas de Olavarría, pues, cuando estuvo en México (1873-1879), Gómez Vergara tenía poco tiempo de residir en la capital de la República Mexicana, por lo que su obra poética, desarrollada en los periódicos, era poco conocida y se concentraba en la versificación política, como indiqué antes; asimismo, a principios de 1874, se dirigió a España para desempeñar el cargo de oficial de la Legación de México, lo que hace dudar de que Adolfo Llanos leyera la obra poética de Gómez Vergara en nuestro país.

\footnotetext{
${ }^{3}$ El peninsular Antonio Fernández Merino publicó Poetas americanos. México. Flores, Hijar, Prieto, Riva Palacio, Peza, Carpio, Altamirano (1886), donde incluyó a Juan Bautista Hijar, quien fue compañero de Gómez Vergara en la Legación de México en España. Llama la atención que, de los siete poetas seleccionados por Fernández Merino, tres se desempeñaron como diplomáticos en Madrid: Hijar, Juan de Dios Peza y Vicente Riva Palacio; los dos primeros tuvieron amistad con Antonio Fernández — según él mismo apunta-, pero dejó fuera a Joaquín Gómez Vergara, quien, como ya lo señalé, además de cubrir las actividades diplomáticas, participó en los círculos literarios madrileños, donde difundió las letras mexicanas y elaboró valiosas crónicas para el periódico mexicano El Porvenir, en el que dio cuenta del ambiente literario y político de la Península. Cabe mencionar que, en el proceso de esta investigación, identifiqué que la literatura mexicana en España tenía más trascendencia que la de otras naciones hispanoamericanas, pues era publicada en forma independiente; prueba de ello es el libro Poetas americanos, aparecido previamente en 1880, donde se presentan de manera conjunta argentinos, bolivianos, chilenos, colombianos, cubanos, ecuatorianos, peruanos, uruguayos y venezolanos.
} 
Los poemas del jalisciense incluidos en el libro de Olavarría se difundieron originalmente en España, ya que, después de que Juan de Dios Peza imprimiera en Madrid su compilación de poetas mexicanos, Vicente Riva Palacio promovió en México la antología El Parnaso mexicano (publicación quincenal editada del 15 de mayo de 1885 al 15 de julio de 1886), obra que el investigador Manuel Sol estudió en sus diversas etapas, y señaló que la primera serie de poemas fue seleccionada por Riva Palacio, mientras que en las ediciones subsecuentes recibió el apoyo de Francisco J. Arredondo (Sol, 2006a: 13-35). Riva Palacio conocía La lira mexicana de Peza que le sirvió como modelo para El Parnaso mexicano, pero cuando estuvo en Madrid en 1886 pudo comparar la selección poética de Peza con las Poesías líricas mejicanas de Olavarría, y encontró a otros poetas que Juan de Dios había dejado fuera. ${ }^{4}$ De ese modo, Riva Palacio conoció los dos poemas de Gómez Vergara: "En el panteón” y "Mis montañas", que probablemente envió a Arredondo para que los integrara a El Parnaso mexicano (Sol, 2006b: 338-348).

La certeza de que los esfuerzos de Olavarría y Llanos por difundir y reivindicar las letras mexicanas en España fructificaron se sustenta en el hecho de que el compositor Climent Cuspinera Oller (1842-1899) realizó la versión catalana de "En el panteón” de Gómez Vergara, que José Ribera Miró (1839-1921) musicalizó como una romanza para canto y piano, mientras que la compañía editorial de Juan Bautista Pujol Riu (1835-1898) la publicó en Barcelona. Dicha composición se localizó en la Biblioteca Digital de la Biblioteca Nacional de España como fascículo. ${ }^{5}$

Cabe anotar que Felipe Pedrell, destacado compositor, crítico e historiador musical, se interesó por difundir, en las páginas de la Ilustración Musical. Hispano-Americana, textos literarios de escritores mexicanos, como Francisco Sosa, Manuel José Othón, José María Vigil, Juan de Dios Peza e Ignacio Manuel Altamirano, con el propósito de unir a España con Hispanoamérica por medio de la música. Al respecto, Rogelio

\footnotetext{
${ }^{4}$ En la edición de Vicente Riva Palacio sólo se incluye "Mis montañas" (1905: 146-147).

${ }^{5}$ Pujol y Compañía Editores distribuían diferentes tipos de música española y extranjera, órganos para iglesias, capillas y salones, instrumentos musicales de orquesta y de banda militar, además ofrecían servicios de reparación para esos productos tanto en Europa como en América. Valga mencionar el afán de Felipe Pedrell y Sabaté (1841-1922), editor de la Ilustración Musical. Hispano-Americana (1888-1897), por incluir la romanza aludida en esta revista, pues el sumario de su número correspondiente al 15 de noviembre de 1891 indica que la sección "Música" contenía dicho material. Sin embargo, al revisar el ejemplar de la Ilustración Musical en la Hemeroteca Digital de la Biblioteca Nacional de España, se constató que tanto "En el panteón. Romanza" como otros materiales ofertados en ese número no se encuentran, lo que lleva a suponer que se entregaron como piezas de colección independientes, debido a que requerían de un papel especial para partituras musicales que implicaba facturarlo en un establecimiento distinto al de la Tipografía La Academia de la Viuda e Hijos de Ullastres y Compañía, donde se elaboró la Ilustración Musical. Hispano-Americana; por ello, la romanza se imprimió con Juan Bautista Pujol y Co. Editores.
} 


\section{“En el panteón”. Poema de Joaquín Gómez Vergara}

Álvarez Meneses documenta que Pedrell sostuvo amistad con el compositor mexicano Gustavo Ernesto Campa (1863-1934), según consta en el archivo del músico español que resguarda las 63 epístolas y tres tarjetas postales que mediaron entre ambos (123150). Gracias a Campa, Pedrell conoció el panorama musical de México de finales del siglo XIx y le dio difusión en la Ilustración Musical, inclusive cuando Campa dejó de comunicarse con Felipe Pedrell, éste suplió la falta de información con aquella contenida en los periódicos mexicanos que recibía: El Imparcial, El Nacional y El Tiempo. De tal modo, los lectores españoles pudieron conocer, a través de la Ilustración Musical, la vida y la obra de los autores mexicanos, como Ricardo Castro, Melesio Morales y Felipe Villanueva, a los que se suman los escritores ya señalados.

Álvarez Meneses enfatiza que Pedrell tenía interés en la obra poética producida en nuestro país, por ello pidió a Campa que fungiera como intermediario para solicitar los textos a los autores y remitirlos al editor. Sin embargo, Campa lamentó que sus esfuerzos fueran infructuosos, pues, aunque algunos letrados aseguraban que le mandarían algún material, lo olvidaban y de nada servía que les reiterara la invitación: "todos, sin exepción [sic] prometen y no cumplen, y de ahí que, para obtener la más insignificante poesía, haya debido insistir hasta enfadar a muchos de ellos" (citado en Álvarez: 131). Esta información permite saber que Pedrell consideró reunir poemas de escritores mexicanos y musicalizarlos para contribuir a la unidad de España y México. ${ }^{6}$

Es probable que, tras la lectura de los poemas de Joaquín Gómez Vergara, compilados ya fuera por Enrique de Olavarría o por Adolfo Llanos, los compositores catalanes optaran por traducir y musicalizar "En el panteón", debido a que el contenido de este poema alude a un sentimiento universal: el dolor de un hijo que pierde a su madre y llora al sepultarla. Mientras que "Mis montañas" cuenta con claves que permiten identificar lugares específicos situados en México, como el Popocatépetl y el Iztaccíhuatl, sin dejar de lado la flora y la fauna regionales, con palabras como zenzontle y huizache, elementos que podían restar interés entre un público europeo;

${ }^{6}$ Entre los aspectos que muestran la importancia de los músicos españoles que difundieron la obra de Gómez Vergara, puede mencionarse la trayectoria de Ribera Miró, destacado compositor de zarzuelas en Barcelona que deslumbró por su desempeño como organista y con el contrabajo, experiencia que, además, transmitió a sus alumnos. En la Sociedad Barcelonesa de Cuartetos ofreció conciertos de música clásica. Su trabajo musical en obras religiosas y de zarzuela fue reconocido con varios premios en certámenes musicales realizados en Barcelona, Cádiz y Valencia. Asimismo, cabe señalar que Pujol Riu sumaba a su oficio de editor los conocimientos musicales que había aprendido en París. En Barcelona, ejerció la docencia en la Escuela Municipal de Música, lo que le permitió fundar una escuela catalana de pianistas. A sus esfuerzos se debe la organización de la primera temporada de conciertos sinfónicos en esa ciudad (1881), así como la inclusión de un ciclo de ópera francesa. Estableció una editorial de música en 1888 y creó una colección para difundir obras melódicas religiosas, para voz y acompañamiento de órgano. 


\section{| Lilia Vieyra Sánchez}

aunque debe considerarse que este grupo de compositores españoles pretendía, precisamente, difundir la inspiración poética de escritores hispanoamericanos, por lo que cobraban relevancia los motivos que incitaban la creación literaria. Vale recordar que en 1891, año en el que apareció el poema en la Ilustración Musical. Hispano-Americana, Gómez Vergara residía en México, a donde había regresado luego de servir en las legaciones de España, Italia y Alemania. Hasta ahora desconozco si los catalanes se comunicaron con el jalisciense y le pidieron permiso para reproducir, traducir y musicalizar su texto. En el caso de que tales conversaciones no se hayan llevado a cabo, es probable que los españoles tomaran el poema de la obra de Olavarría o de Llanos, como apunté antes.

Las versiones de "En el panteón" que aquí se transcriben corresponden al libro de Enrique de Olavarría y a la composición de Climent Cuspinera Oller. ${ }^{7}$

\section{Bibliografía}

Álvarez Meneses, Rogelio

"La presencia de México en la revista Ilustración musical Hispano-Americana a través de la corresponsalía de Gustavo E. Campa", en Cuadernos de Música Iberoamericana, volumen XXII (julio-diciembre de 2011), 123-150.

BARbero, Juan E.

Lira de la juventud. Poesías mexicanas. México: Imprenta de La Bohemia Literaria, 1872 (Biblioteca de El Eco de Ambos Mundos).

Elies I. Busqueta, Pere

Canigo: diccionario catalán-castellano, castellano-catalán. Barcelona: R. Sopena, 1996.

\section{En el panteón}

Romanza. Poesía de Joaquín Gómez Vergara. Música de José Ribera. Barcelona: Juan Bta. Pujol \& Co. Editores [1891].

Enciclopedia universal ilustrada europeo-americana

Volumen 42. Madrid: Espasa Calpe, s. a., 1262-1266.

Fernández Merino, Antonio

Poetas americanos. México. Flores, Hijar, Prieto, Riva Palacio, Peza, Carpio, Altamirano. Barcelona: Tipografía La Academia de E. Ullastres, 1886.

Gómez Vergara, Joaquín

"En el panteón", en Enrique de Olavarría y Ferrari. Poesías líricas mejicanas de Isabel Prieto, Rosas, Sierra, Altamirano, Flores, Riva Palacio, Prieto y otros autores. Madrid: Dirección y Adminis-

${ }^{7}$ La transcripción de la traducción catalana de Climent Cuspinera se hizo a partir de la incluida en las partituras, que fue cotejada con el diccionario catalán de Pere Elies (1996). 


\section{“En el panteón”. Poema de Joaquín Gómez Vergara}

tración, 1878, 110-111 (Biblioteca Universal. Colección de los Mejores Autores Antiguos y Modernos, Nacionales y Extranjeros, tomo XLV).

"Mis montañas", en Enrique de Olavarría y Ferrari. Poesías líricas mejicanas de Isabel Prieto, Rosas, Sierra, Altamirano, Flores, Riva Palacio, Prieto y otros autores. Madrid: Dirección y Administración, 1878, 108-110 (Biblioteca Universal. Colección de los Mejores Autores Antiguos y Modernos, Nacionales y Extranjeros, tomo XLV).

Olavarría y Ferrari, Enrique de

El arte literario en México. Noticias biográficas y críticas de sus más notables escritores. $2^{\text {a }}$ edición. Madrid: Espinosa Bautista, editores [1878a].

Poesías líricas mejicanas de Isabel Prieto, Rosas, Sierra, Altamirano, Flores, Riva Palacio, Prieto y otros autores. Madrid: Dirección y Administración, 1878b (Biblioteca Universal. Colección de los Mejores Autores Antiguos y Modernos, Nacionales y Extranjeros, tomo XLV).

Peza, Juan de Dios

La lira mexicana. Colección de poesías de autores contemporáneos. Prólogo de Antonio Balbín de Unquera. Apreciaciones de Castelar, Campoamor, Grillo, Núñez de Arce, Selgas. Madrid: R. Velasco, impresor, 1879.

Poetas americanos

Madrid: Dirección y Administración, 1880 (Biblioteca Universal. Colección de los Mejores Autores, Antiguos y Modernos, Nacionales y Extranjeros, tomo LX).

Riva Palacio, Vicente

El Parnaso mexicano. (Los trovadores de México). Poesías líricas de autores contemporáneos. $2^{\mathrm{a}}$ edición. México: Maucci, 1905.

Sol, Manuel

"Introducción", en El Parnaso mexicano. Primera serie I. México: Consejo Nacional para la Cultura y las Artes/Universidad Nacional Autónoma de México/Instituto Mexiquense de Cultura/Instituto de Investigaciones Dr. José María Luis Mora, 2006, 13-35.

"Edición, introducción e índices", en Vicente Riva PaLacio. El Parnaso mexicano. Segunda serie II. Poesías escogidas de varios autores coleccionadas bajo la dirección de Vicente Riva Palacio por Francisco 7. Arredondo. Coordinador de la obra José Ortiz Monasterio. México: Consejo Nacional para la Cultura y las Artes/Universidad Nacional Autónoma de México/Instituto Mexiquense de Cultura/Instituto de Investigaciones Dr. José María Luis Mora, 2006, 338-348.

Vieyra SÁnchez, Lilia

"Un episodio en la fundación de la Academia Mexicana Correspondiente de la Española: la crítica de Joaquín Gómez Vergara (1875)”, en Guadalupe Curiel Defossé y Belem Clark de Lara. Aproximaciones a una historia intelectual. Revistas y asociaciones literarias mexicanas del siglo XIX. México: Universidad Nacional Autónoma de México, Instituto de Investigaciones Bibliográficas, 2016, 127-150. 



\section{En el panteón}

Joaquín Gómez Vergara

Llorando, un día aquí dejé a mi madre, transido de dolor...

La tarde estaba triste, sí, ¡muy triste!

Tan triste como yo.

Las campanas doblaban a lo lejos, y al ocultarse, el sol

doraba con sus últimos fulgores

de los sauces el fúnebre verdor.

El viento susurraba entre las hojas

con tristísimo son...

Y los ramos de flores amarillas

mi llanto marchitó.

Con ella vine... y la dejé ¡muy sola!

Y lleno de aflicción

solo tornéme, y en mi hogar desierto

me faltaron la vida y el calor.

Hoy vuelvo aquí después de muchos años,

este es el panteón;

pero esa tumba encierra otro cadáver

y rota está la cruz que clavé yo.

La piedra en que aquel nombre idolatrado

grabé con santo amor,

no ocupa ya su sitio... ¡Madre mía!

¡Madre de mi alma!... Adiós!!! 


\section{En el panteón \\ Romanza $^{1}$}

Versión catalana de C. Cuspinera

Plorant, un jorn aquí deixí ma mare

de dol tot ple mon cor,

de dol tot ple mon cor.

La tarda era trista, sí, molt trista!

com trist ho estava jo.

Les campanes brandaven planyívoles

i, en amagar-se, el sol

daurava amb els seus rajos d'or en les prades

dels salzes llur fúnebre verdor.

El vent entre llurs fulles murmurava

amb fatídica, amb fatídica remor,

i les flors que amb les meves llàgrimes mullava

morien, morien, morien, pobres flors!

Vaig venir amb ella i la deixí soleta,

vaig venir amb ella i la deixí soleta, soleta!

I ple el cor d'aflicció,

jo vaig tornar-me'n trist i solitari

i mancant-me la vida i la calor.

Jo vaig tornar-me'n trist i solitari

i mancant-me la vida i la calor.

Molts anys després avui aquí jo hi torno,

[i] trobo son llit de mort.

Trobo son llit de mort.

Mes eixa tomba inclou un altre cadàver.

Trencada està la creu que claví jo.

La pedra a on $^{2}$ son nom que idolatrava

gravà mon dolor greu.

No ocupa ja son lloc, mare meva!

Mare de ma vida!

Adéu! Adéu!

Mare meva, mare de ma vida!

Adéu! Adéu! Adéu!

\footnotetext{
${ }^{1}$ La revisión y corrección del texto en catalán estuvo a cargo de Bernardo Berruecos Frank y David C. Redón.

${ }^{2}$ En la partitura aparece el término ahont, que no se incluye en ningún diccionario actual; por ello, se enmendó y actualizó el texto, con el objetivo de hacerlo más legible.
} 


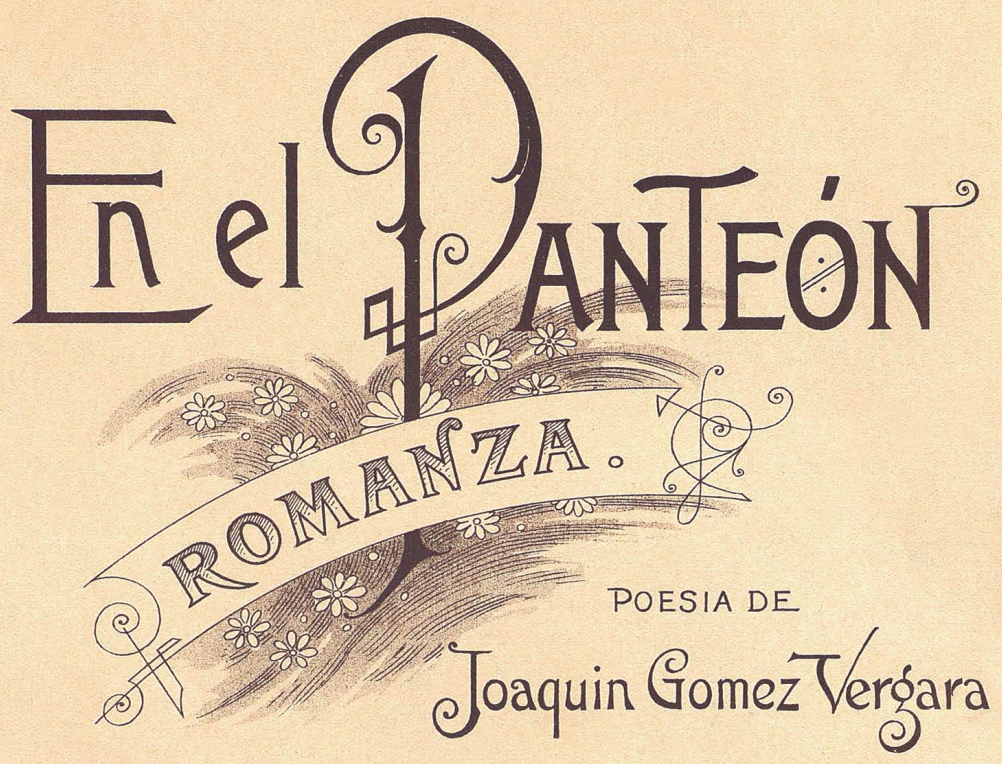

(7) úsica de

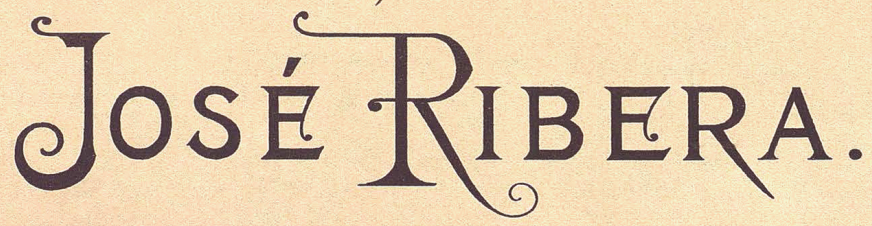

Ptas. 6.

BARCELONA JUAN BTA PUJOL \& C EDITORES

$1 \& 3$ Puerta del Angel $1 \& 3$.

Propiedad para todos los paises.

Depositado con arreglo à los tratados internacionales.

uedan reservados todos los derechos de ejecucio

163. 


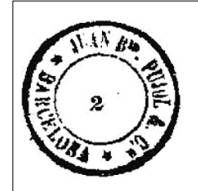

\section{EN EL PANTEÓN. Romanza.}

Poesia de Joaquin Gomez Vergara.

Versió catalana de C. Cuspinera.

Andante.
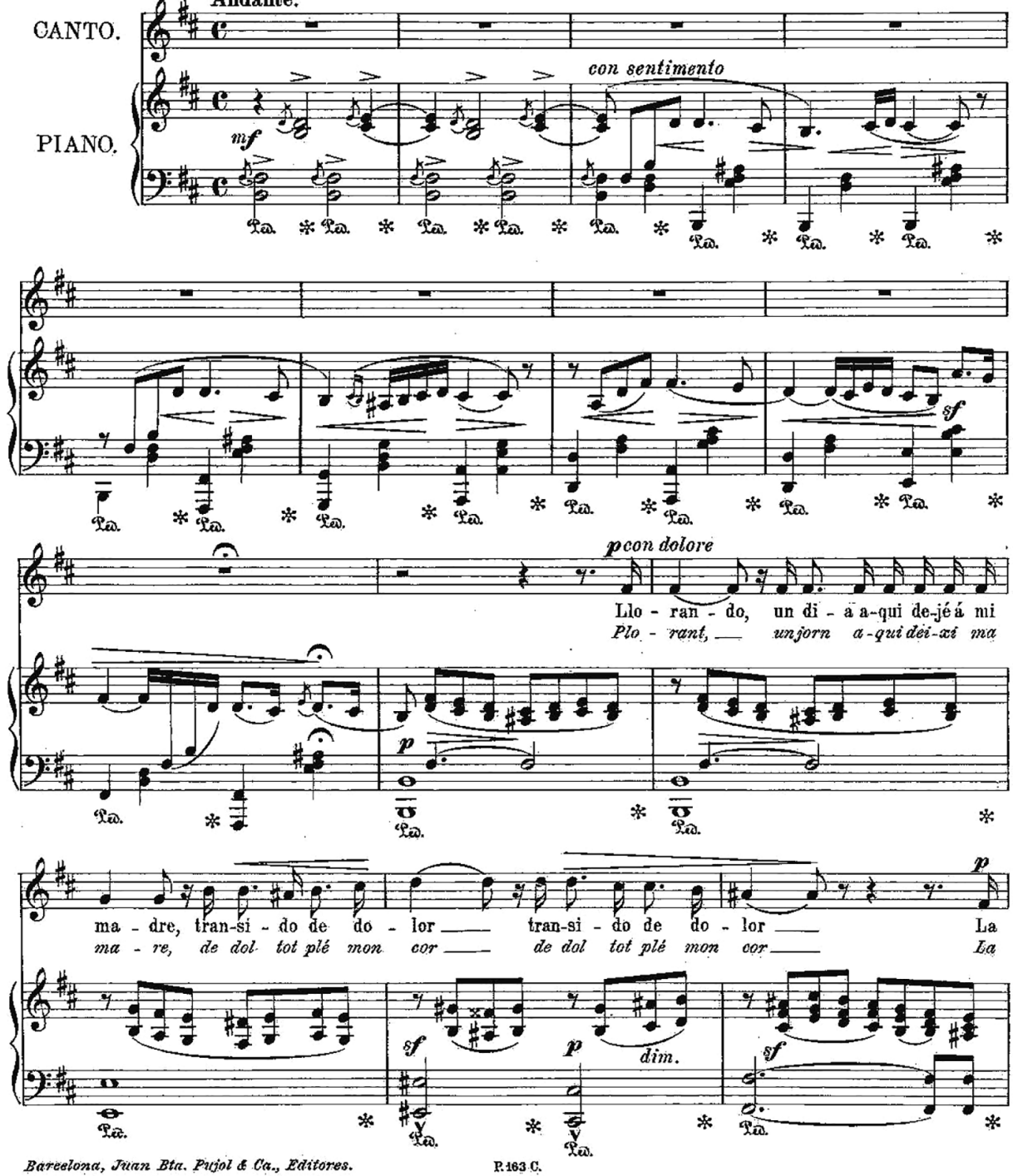

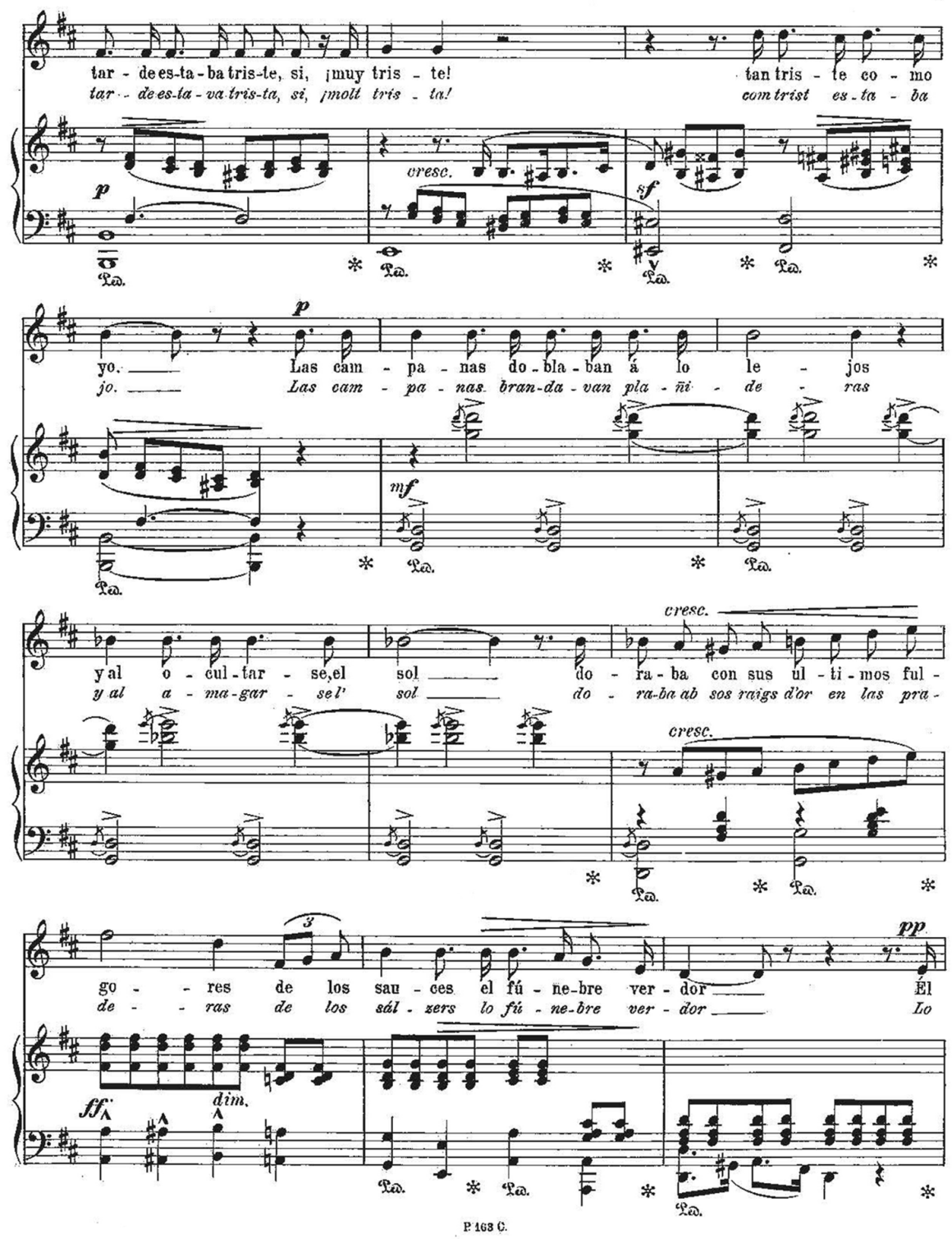


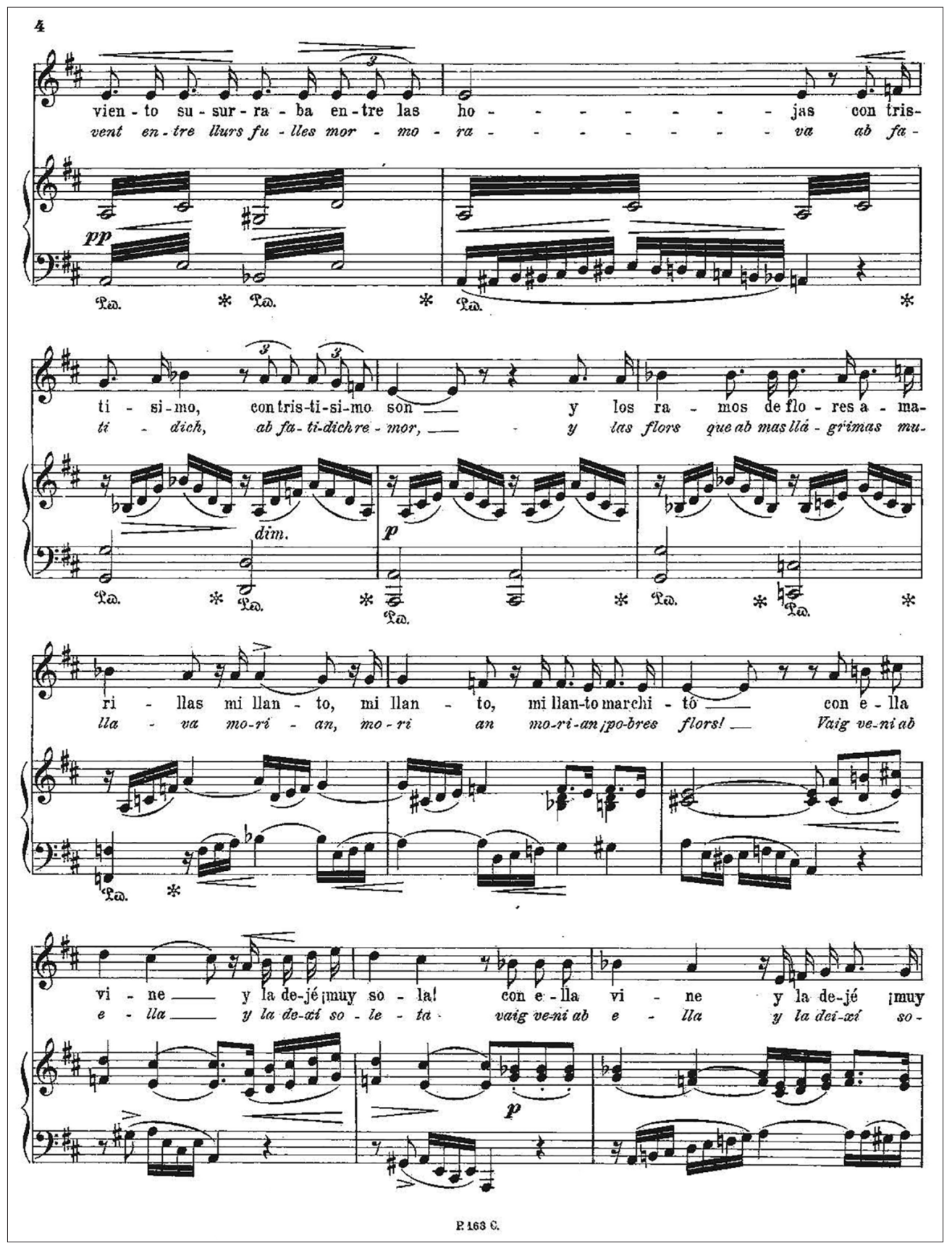




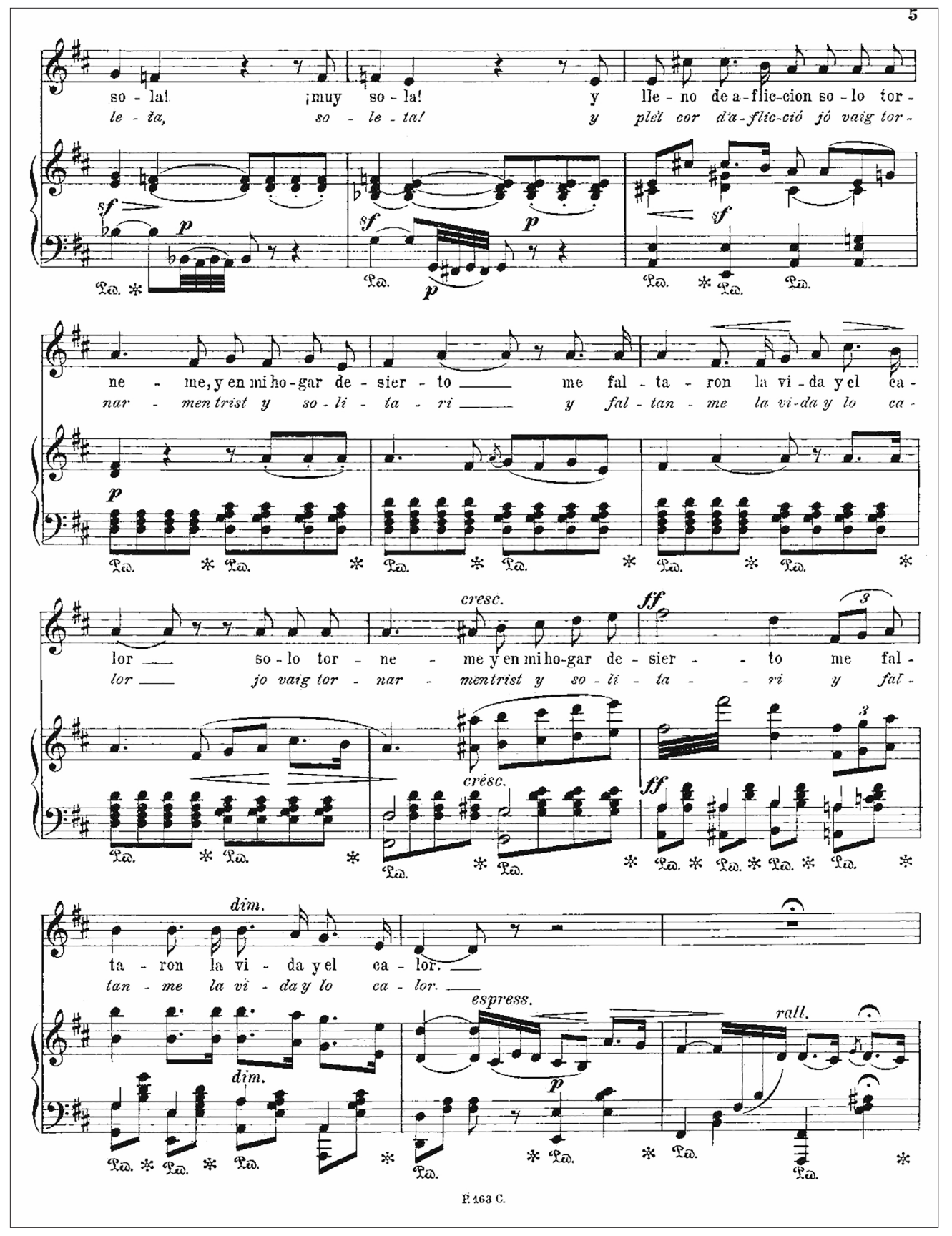




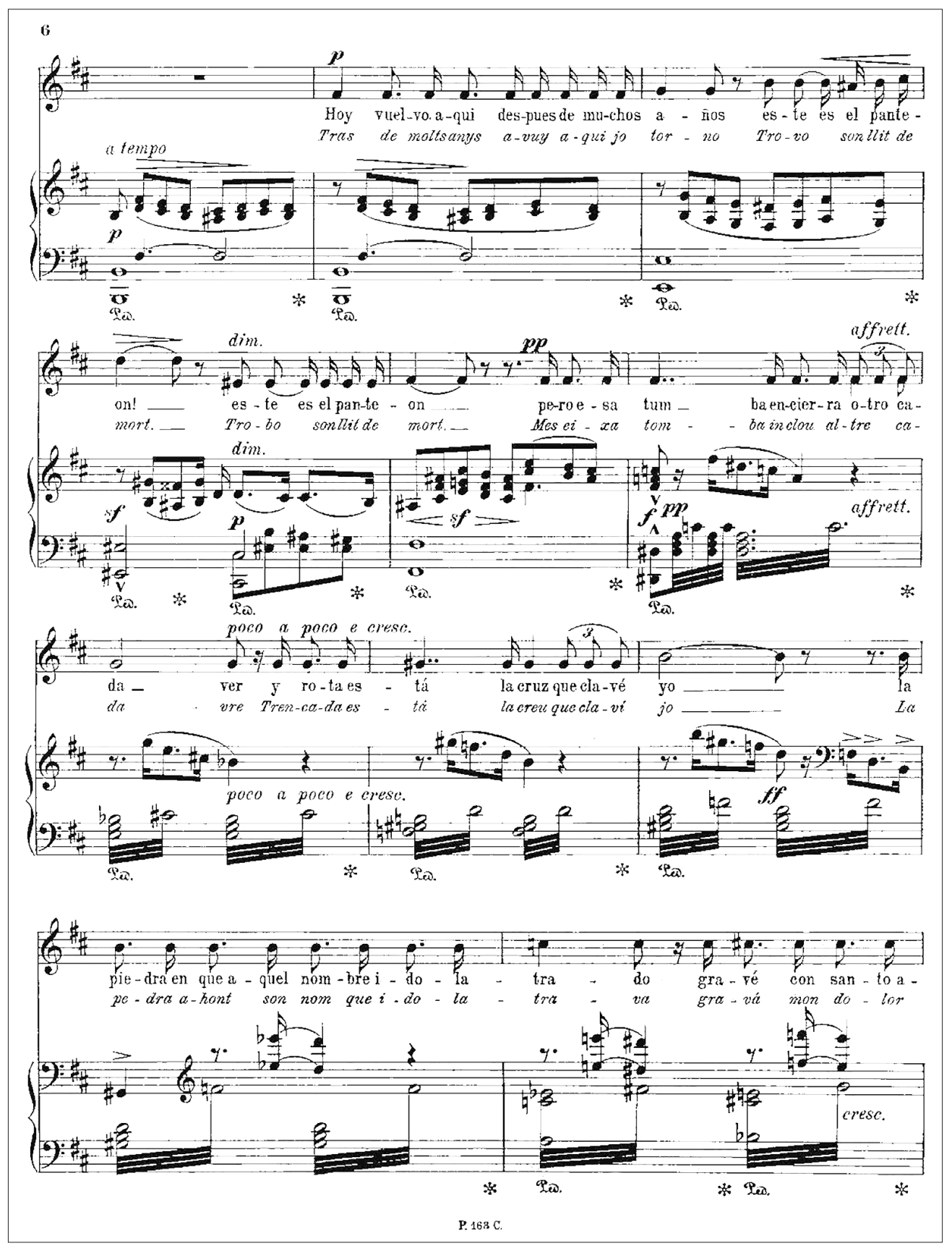

90 (an)ecdótica vol. IV, núm. 1, enero-junio 2020 


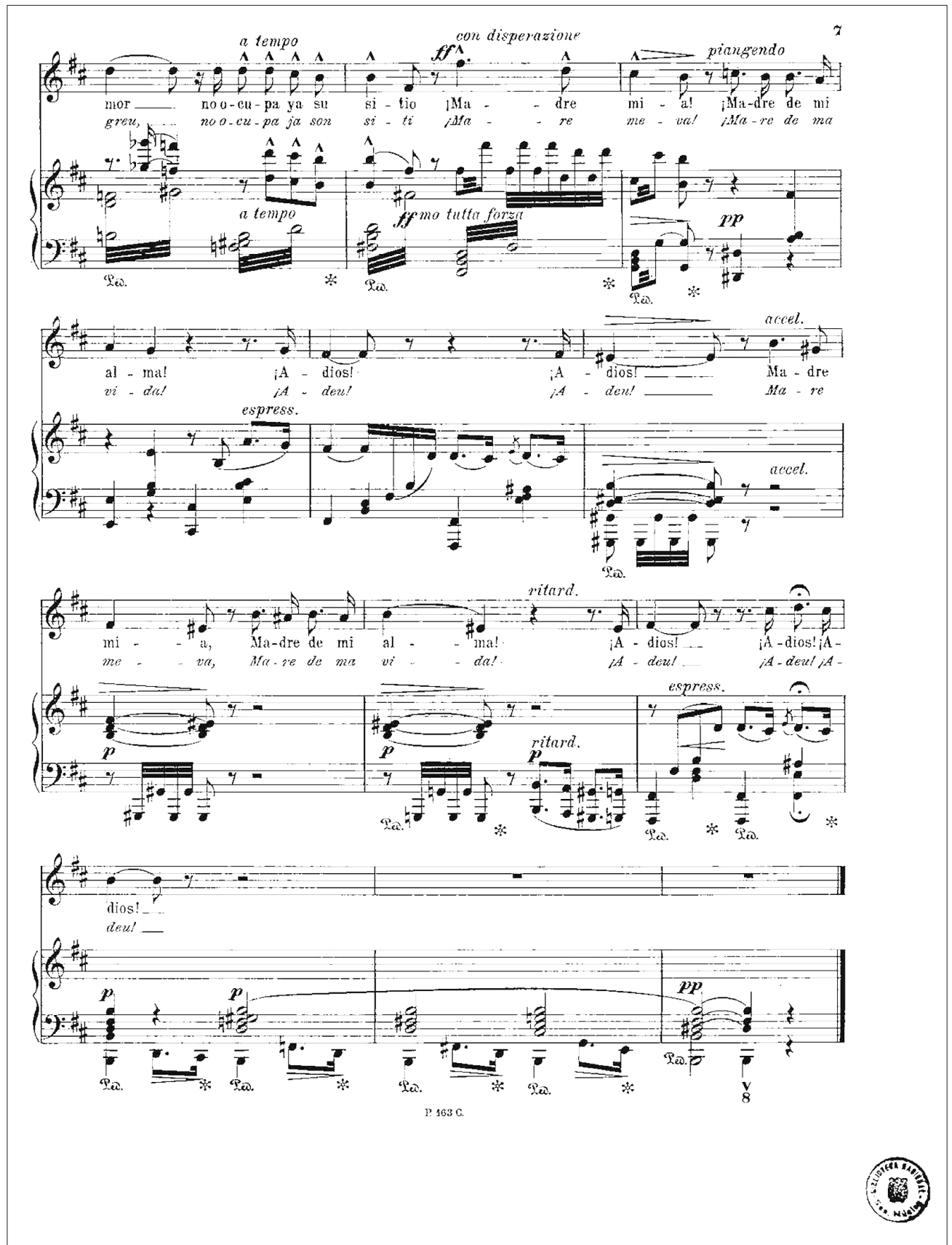

